\title{
On the Origin of the Improved Ruthenium Stability in $\mathrm{RuO}_{2}-\mathrm{IrO}_{2}$ Mixed Oxides
}

\author{
Olga Kasian, ${ }^{\mathrm{a}, \mathrm{b}, \mathrm{z}}$ Simon Geiger, ${ }^{\mathrm{a}}$ Philipp Stock, ${ }^{\mathrm{a}}$ George Polymeros, ${ }^{\text {a Benjamin Breitbach, }}{ }^{\mathrm{a}}$ \\ Alan Savan, ${ }^{c}$ Alfred Ludwig, ${ }^{c}$ Serhiy Cherevko, ${ }^{\text {a,d }}$ and Karl J. J. Mayrhofer ${ }^{a, d, e, *}$ \\ ${ }^{a}$ Max-Planck-Institut für Eisenforschung GmbH, 40237 Düsseldorf, Germany \\ ${ }^{b}$ Ukrainian State University of Chemical Technology, 49005 Dnipropetrovsk, Ukraine \\ ${ }^{c}$ Institute for Materials, Ruhr-Universität Bochum, 44801 Bochum, Germany \\ ${ }^{d}$ Helmholtz-Institute Erlangen-Nürnberg for Renewable Energy (IEK-11), Forschungszentrum Jülich, \\ 91058 Erlangen, Germany \\ ${ }^{e}$ Department of Chemical and Biological Engineering, Friedrich-Alexander-Universität Erlangen-Nürnberg, \\ 91058 Erlangen, Germany
}

\begin{abstract}
High oxygen evolution reaction activity of ruthenium and long term stability of iridium in acidic electrolytes make their mixed oxides attractive candidates for utilization as anodes in water electrolyzers. Indeed, such materials were addressed in numerous previous studies. The application of a scanning flow cell connected to an inductively coupled plasma mass spectrometer allowed us now to examine the stability and activity toward oxygen evolution reaction of such mixed oxides in parallel. The whole composition range of Ir-Ru mixtures has been covered in a thin film material library. In the whole composition range the rate of Ru dissolution is observed to be much higher than that of Ir. Eventually, due to the loss of Ru, the activity of the mixed oxides approaches the value corresponding to pure $\mathrm{IrO}_{2}$. Interestingly, the loss of only a few percent of a monolayer in $\mathrm{Ru}$ surface concentration results in a significant drop in activity. Several explanations of this phenomenon are discussed. It is concluded that the herein observed stability of mixed Ir-Ru oxide systems is most likely a result of high corrosion resistance of the iridium component, but not due to an alteration of the material's electronic structure.

(C) The Author(s) 2016. Published by ECS. This is an open access article distributed under the terms of the Creative Commons Attribution 4.0 License (CC BY, http://creativecommons.org/licenses/by/4.0/), which permits unrestricted reuse of the work in any medium, provided the original work is properly cited. [DOI: 10.1149/2.0131611jes] All rights reserved.
\end{abstract}

Manuscript submitted May 5, 2016; revised manuscript received June 17, 2016. Published July 12, 2016. This paper is part of the JES Focus Issue on Electrolysis for Increased Renewable Energy Penetration.

Renewable primary energies such as solar energy, wind energy and ocean energy receive more and more attention and are increasingly installed around the world. ${ }^{1-3}$ It is anticipated that renewables will eventually replace traditional fossil fuel-burning and nuclear power plants. However, intermittent power supply of renewables means that energy needs to be buffered. Thereby, hydrogen produced by water electrolysis is considered as an ideal energy carrier to adjust the balance between the generation of power by renewable primary energy and energy demand for end-use. ${ }^{3-5}$ Currently, acidic proton exchange membrane water electrolysis (PEMWE) is considered as a promising technology for this purpose. However, the widespread use of PEMWE is hindered by high capital costs, low efficiency, and shortages related to performance deterioration with time. ${ }^{6}$ In this connection the nature of electrocatalysts and the procedure of their production and application conditions play a critical role. Materials used as electrocatalysts must be as active as possible to improve efficiency, while at the same time they need to be stable to maintain this efficiency throughout the lifetime of the electrolyzer. This is especially critical for materials catalyzing the anodic oxygen evolution reaction (OER), because of the detrimental positive potential and highly corrosive acidic environment. Only a few catalysts are able to withstand these harsh conditions, while providing sufficient activity, conductivity and mechanical stability. In fact, only iridium oxide anodes are proven to provide the required longevity of operation. On the other hand, ruthenium shows the highest electrocatalytic activity toward this reaction. ${ }^{7,8}$ During the last decades, the electrochemical and surface properties of anodes based on these metals and their oxides were addressed in numerous research works. ${ }^{8-37}$ Especially, the previous attempts of combining the stability of iridium with the activity of ruthenium using their alloys or mixed oxides for the development of promising OER catalyst must be mentioned..$^{34,38-49}$ However, the data presented in literature is to a major extent non-systematic and in some cases is in disagree-

\footnotetext{
*Electrochemical Society Member.

${ }^{\text {z} E-m a i l: ~ o . k a s i a n @ m p i e . d e ~}$
}

ment. In particular, the question of surface segregation of iridium is a subject of numerous debates. While most researchers agree that segregation takes place in the $\mathrm{Ir}-\mathrm{Ru}$ mixed oxides, ${ }^{42,46,47}$ other reports claim its absence. ${ }^{44}$ Nevertheless, all works come to the conclusion that the stability of $\mathrm{RuO}_{2}$ may be improved significantly by addition of $\mathrm{IrO}_{2}$, at least on time scales typically employed in the lab. Owing to a lack of sensitive analytical techniques able to detect low amounts of dissolved elements, the conclusion was typically drawn from evaluation of current or potential profiles during accelerated degradation tests. The disadvantage of this approach is its relatively poor selectivity. Since tests are performed at high anodic potentials, degradation can be equally well attributed to corrosion of the active layer or to mechanical degradation due to intensive evolution of oxygen gas bubbles. Moreover, in case of metal ions dissolution from the mixed oxide system, it cannot provide information on specific dissolution of the particular element responsible for the overall catalyst degradation.

In the present work a scanning flow cell (SFC) connected to an inductively coupled plasma mass spectrometer (ICP-MS) is utilized to examine stability and OER activity of $\mathrm{Ir}-\mathrm{Ru}$ mixed oxides covering the whole composition range. Unlike the previous attempts, the current work presents partial dissolution rates of $\mathrm{Ru}$ and Ir measured on-line during OER. This information is used to fill the gap in understanding of the effect of composition changes on the stability activity relationship for ruthenium-iridium mixed oxide anodes.

\section{Experimental}

The thin-film material libraries were deposited by combinatorialmagnetron sputtering (DCA Instruments, Turku, Finland) using a confocal co-deposition approach. To prepare samples with a minimal surface roughness, smooth substrates of single crystal Si wafers (100) with $1.5 \mu \mathrm{m}$ thermal $\mathrm{SiO}_{2}$ as a buffer layer against silicide formation were used. Before loading to the deposition chamber the substrates were ultrasonically cleaned with acetone and isopropanol and dried 
with compressed dry air. The base vacuum before deposition was $2.5 \times 10^{-6} \mathrm{~Pa}$. The 4 inch targets of Ti $(99.995 \%$, FHR, Germany), $\mathrm{Ru}$ (99.95\%, EvoChem, Germany) and Ir (99.9\%, Evochem, Germany) were precleaned by sputtering against closed shutters prior to deposition. Ar (99.999\%) was used as the sputter gas and the chamber pressure was regulated to $0.67 \mathrm{~Pa}$ at room temperature. A 20 $\mathrm{nm}$ Ti adhesion layer was deposited at $200 \mathrm{~W}$ RF with a rate of $0.025 \mathrm{~nm} \mathrm{~s}^{-1}$ and a constant rotation of $20 \mathrm{rpm}$, in order to produce uniform layer thicknesses from the confocal cathode arrangement. Then Ir and Ru were deposited simultaneously at $250 \mathrm{~W} \mathrm{RF}$ and a rate of $0.062 \mathrm{~nm} \mathrm{~s}^{-1}$ and at $200 \mathrm{~W} \mathrm{RF}$ and $0.068 \mathrm{~nm} \mathrm{~s}^{-1}$, respectively. Because of the cathode tilt with respect to the substrate surface due to the confocal cathode arrangement, thickness gradients are produced when the substrate is static which result in the composition ratio of the co-deposited elements in the mixture varying continuously. The resulting thickness of the obtained coating was approximately 250 $\mathrm{nm}$. The composition of the obtained libraries was confirmed using EDX mapping (INCA X-act, Oxford Instruments, U.K.) and X-ray photoelectron spectroscopy (XPS).

After deposition, the samples were treated thermally in air at $600^{\circ} \mathrm{C}$ during 5 hours. This procedure leads to the formation of the oxide films with different $\mathrm{Ru}$ and Ir content. ${ }^{7}$

XPS measurements were performed (Quantera II, Physical Electronics, Chanhassen, MN, USA) applying a monochromatic Al Ka X-ray source (1486.6 eV) operating at $15 \mathrm{kV}$ and $25 \mathrm{~W}$. The binding energy scale was referenced to the $\mathrm{C} 1 \mathrm{~s}$ signal at 285.0 eV. Analysis of the spectra was carried out with the Casa XPS (http://www.casaxps.com/) software.

Prepared Ir-Ru oxide libraries served as the working electrodes in the scanning flow cell (SFC) - inductively coupled plasma mass spectrometer (ICP-MS, NexION 300X, Perkin Elmer) based setup, described in detail previously. ${ }^{50}$ The exposed area on the working electrode was $1 \times 10^{-2} \mathrm{~cm}^{2}$ as defined by the size of the opening of the electrochemical SFC. All presented data are normalized to the geometric area of the working electrode assuming that the roughness of the thin-film sputtered electrodes is small. A graphite rod, placed in the inlet channel of the SFC, was used as the counter electrode. A commercial saturated $\mathrm{Ag} / \mathrm{AgCl}$ electrode (Metrohm, Germany) was utilized as the reference electrode. All reported potentials are referred to the reversible hydrogen electrode (RHE) potential, which was measured versus the $\mathrm{Ag} / \mathrm{AgCl}$ electrode using a polycrystalline platinum foil (99.99\%, MaTeck, Germany) in the corresponding electrolyte after saturation with hydrogen.

All electrochemical measurements were carried out in $0.1 \mathrm{M}$ $\mathrm{H}_{2} \mathrm{SO}_{4}$ solution prepared by dilution of concentrated sulfuric acid (Suprapur 96\% $\mathrm{H}_{2} \mathrm{SO}_{4}$, Merck, Germany) in ultrapure water (PureLab Plus system, Elga, $18 \mathrm{M} \Omega \mathrm{cm}$, TOC $<3 \mathrm{ppb}$ ). During measurements, the electrolyte was pumped with a constant flow rate of ca. $190 \mu \mathrm{L}$ $\mathrm{min}^{-1}$ from a reservoir of argon-saturated electrolyte to the V-shaped channels of the polycarbonate cell and then further downstream. The electrolyte was mixed with an internal standard in a Y-connector (mixing ratio 1:1) after the electrochemical cell, and was then directly introduced into the ICP-MS. As internal standards for detection of ${ }^{102} \mathrm{Ru}$ and ${ }^{193} \mathrm{Ir}$ isotopes, $10 \mu \mathrm{g} \mathrm{L}^{-1}$ of ${ }^{103} \mathrm{Rh}$ or ${ }^{187} \mathrm{Re}$ were used, respectively. Calibration of the ICP-MS was performed on each experiment day prior to electrochemical measurements. The potentiostat (Gamry Reference 600, USA), electrolyte, gas flow, and SFC components were automatically controlled using an in-house built LabVIEW software. ${ }^{51}$ This enabled after several manually controlled investigations, screening of the general behavior in the relevant parameter space by fully automatic and highly reproducible measurements with pre-defined protocols for direct comparison of the different materials. The following experimental protocol was used for electrodes in OER studies. Firstly, the electrodes were polarized at $\mathrm{E}=1.20 \mathrm{~V}_{\mathrm{RHE}}$ during $3 \mathrm{~min}$ for initial stabilization. Afterwards, the potential was swept from $\mathrm{E}=1.20 \mathrm{~V}_{\mathrm{RHE}}$ to a value corresponding to a current density $\mathrm{j}=5 \mathrm{~mA} \mathrm{~cm}^{-2}$ with the scan rate of $10 \mathrm{mV} \mathrm{s}^{-1}$. After that, electrodes were polarized at $1 \mathrm{~mA} \mathrm{~cm}^{-2}$ during $5 \mathrm{~min}$. Then the potential sweep from $\mathrm{E}=1.20 \mathrm{~V}_{\mathrm{RHE}}$ to a potential corresponding to a current density $\mathrm{j}=5 \mathrm{~mA} \mathrm{~cm}^{-2}$ was performed with the scan rate of $10 \mathrm{mV} \mathrm{s}^{-1}$ in order to understand the change in electrochemical behavior of electrodes after anodic polarization. At least three measurements were done for each spot of the same composition to ensure the reproducibility of the results.

\section{Results}

Characterization of $\mathrm{IrO}_{2}-\mathrm{RuO}_{2}$ libraries by $\mathrm{X}$-ray photoelectron spectrometry.-XPS wide-scans (not shown) were recorded on asdeposited and thermally oxidized Ir-Ru composition-gradient thin films. Additionally, the thermally oxidized electrodes were analyzed after an additional electrochemical treatment. In all cases, elements such as iridium, ruthenium, oxygen and carbon were found on the surface. Comparing the spectra of as-deposited and oxidized libraries, no oxidation linked variation in $\mathrm{Ir}-\mathrm{Ru}$ ratio was found. The representative narrow-scans of $\mathrm{Ir}$ and $\mathrm{Ru}$ from the thermally treated gradients containing 5, 50 and 75 at.\% of Ir are shown in Figs. 1a and 1b, respectively. For all samples, the $\mathrm{Ir} 4 \mathrm{f}$ and $\mathrm{Ru} 3 \mathrm{~d}$ peaks are centered at ca. $61.6 \mathrm{eV}$ and $280.7 \mathrm{eV}$, respectively, indicating the formation of corresponding oxides. ${ }^{13,52-54}$ No change in symmetry of Ir 4f peak was observed for spots with various $\mathrm{Ir}-\mathrm{Ru}$ ratios, so the main lines and their shake-up satellites in Ir $4 \mathrm{f}$ level originate only from Ir in the oxidation state $+4 .{ }^{54,55}$ Hence, independent on the amount of Ir and $\mathrm{Ru}$ in the samples, their oxidation states stay constant and correspond to those of the pure oxides. Interestingly, we did not observe any change in the Ir-Ru atomic ratio. Therefore, absence of a significant segregation of any of the elements within a thin surface layer during thermal treatment may be concluded. It should be noted, however, that the sensitivity of XPS is insufficient to prove or disprove reorganization of $\mathrm{Ir}$ and $\mathrm{Ru}$ atoms in this layer, i.e. to answer the question if the composition of the topmost atomic layers is identical to the bulk composition or not. Energetic positions of both $\mathrm{Ru} 3 \mathrm{~d}$ and $\mathrm{Ir} 4 \mathrm{f}$ lines have not changed after the electrochemical treatment (data is not shown) indicating that oxidation states of metals remain the same after the anodic polarization.

The narrow-scans of the $\mathrm{O} 1 \mathrm{~s}$ level from the as-oxidized and electrochemically pretreated electrodes are presented in Figs. 1c and 1d, respectively. Two resolved components in the spectra correspond to $\mathrm{O}$ in the oxide lattice (at lower binding energies) and $\mathrm{O}$ from $\mathrm{OH}$ groups and/or adsorbed on the electrode surface water (at higher binding energies). In the thermally oxidized samples the ratio between these components remains the same in the whole Ir-Ru composition range. With increase in Ir concentration in the gradient, binding energy of the lattice oxygen peak shifts gradually from the values corresponding to pure $\mathrm{RuO}_{2}{ }^{52}$ to those of pure $\mathrm{IrO}_{2}{ }^{13}$. However, the spectra change drastically after the anodic polarization. Unlike $\mathrm{Ru} 3 \mathrm{~d}$ and $\mathrm{Ir} 4 \mathrm{f}$ spectra shown in Figs. 1a and 1b, a shift to higher values is observed for the $\mathrm{O}$ 1s level from the gradient samples (but not pure oxides) before

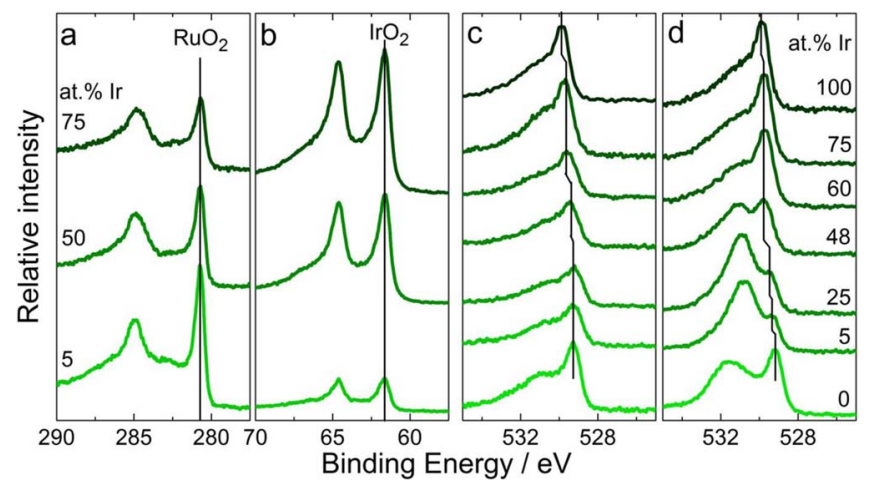

Figure 1. The XPS spectra of the Ru 3d (a), Ir $4 \mathrm{f}(\mathrm{b})$ and $\mathrm{O} 1 \mathrm{~s}$ (c, d) levels for thermally prepared oxide samples with different Ir and Ru ratio before (c) and after anodic polarization (d). 
Table I. XPS binding energies $( \pm 0.05 \mathrm{eV})$ and contribution of adsorbed oxygen-containing species in $\mathrm{O}$ 1s level depending on the Ir-Ru ratio in mixed oxides.

As prepared

\begin{tabular}{ccc}
\cline { 2 - 3 } Ir, at.\% & O 1s, eV & Contribution of $\mathrm{OH}$ groups in O 1s level, \\
\hline 100 & 529.80 & 30 \\
75 & 529.60 & 30 \\
60 & 529.60 & 30 \\
48 & 529.40 & 30 \\
25 & 529.20 & 30 \\
5 & 529.20 & 30 \\
0 & 529.20 & 35
\end{tabular}

and after the electrochemical treatment (Fig. 1d, Table I). Additionally, while the measurement areas with a high amount of Ir stay practically intact, there is a significant increase in the $\mathrm{OH} / \mathrm{O}$ and/or $\mathrm{H}_{2} \mathrm{O} / \mathrm{O}$ ratio for the measurement areas with 60 at.\% of Ir and lower. Corresponding ratios for selected gradients representing the whole composition range are summarized in Table I. The observed variation can be assigned to the difference in the oxygen affinity for Ir and $\mathrm{Ru}$. Unlike for $\mathrm{IrO}_{2}$, an increase of the contribution of $\mathrm{OH}$ species in the overall O1s signal after anodic polarization was observed in the case of $\mathrm{RuO}_{2}$ prepared by the thermal decomposition of the respective salt. ${ }^{56}$

Oxygen evolution reaction at $\mathrm{IrO}_{2}-\mathrm{RuO}_{2}$ mixed oxide electrodes.-Fig. 2a shows polarization curves recorded on the composition-gradient samples. As a criterion describing activity of the electrodes, the potential value at a current density of $5 \mathrm{~mA} \mathrm{~cm}-2$ is adopted in the current work (Fig. 2b, curve 1). Additionally, the potential at the end of the $5 \mathrm{~min}$. long anodic polarization step at $1 \mathrm{~mA} \mathrm{~cm}^{-2}$ was used (Fig. 2c). Both measurements are in good agreement. In short, with increasing Ir content in the gradient, the potential shifts to higher anodic values and, hence, the activity of the electrodes toward the OER decreases.

The electrode stability was tested (a) by recording the evolution of current and dissolution signal with time during the 5 min long anodic polarization step at $1 \mathrm{~mA} \mathrm{~cm}{ }^{2}$ (data is not shown) and (b) by comparing potentials at $5 \mathrm{~mA} \mathrm{~cm}{ }^{-2}$ before and after the potentiostatic step
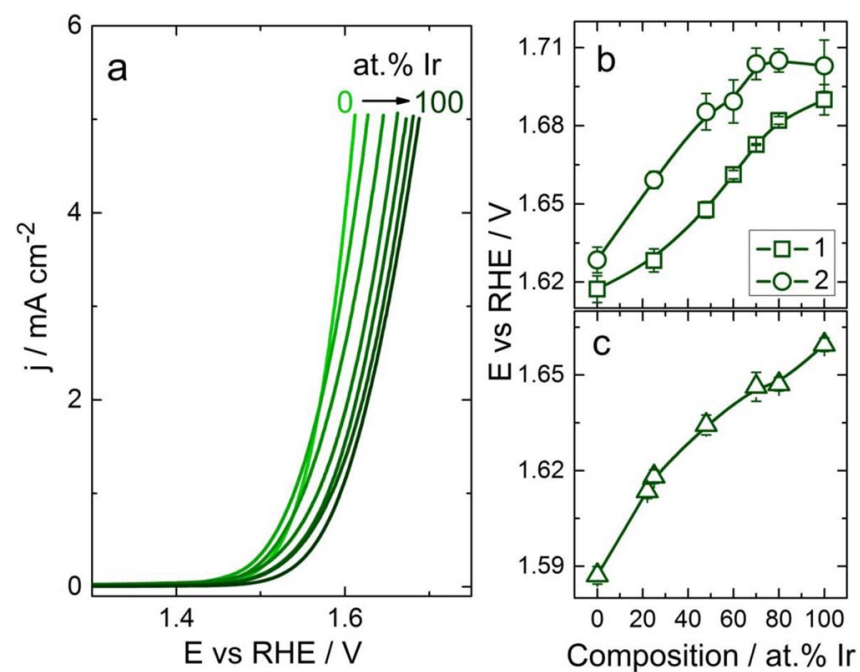

Figure 2. (a) Quasi steady-state anodic polarization curves $\left(10 \mathrm{mV} \mathrm{s}^{-1}\right)$ for $\mathrm{IrO}_{2}-\mathrm{RuO}_{2}$ electrodes with different $\mathrm{Ir} / \mathrm{Ru}$ ratio in $0.1 \mathrm{M} \mathrm{H}_{2} \mathrm{SO}_{4}$ solution. (b) Variation of the potential, at a current density of $5 \mathrm{~mA} \mathrm{~cm}-2$, before (curve 1) and after (curve 2) $5 \mathrm{~min}$ anodic polarization at $1 \mathrm{~mA} \mathrm{~cm}^{-2}$. (c) Corresponding potential at the end of the polarization at $1 \mathrm{~mA} \mathrm{~cm}^{-2}$, as a function of electrode composition.
After anodic polarization

\begin{tabular}{cc}
\hline $\mathrm{O} 1 \mathrm{~s}, \mathrm{eV}$ & Contribution of OH groups in O 1s level, \% \\
\hline 529.80 & 30 \\
529.70 & 30 \\
529.70 & 35 \\
529.70 & 47 \\
529.40 & 70 \\
529.30 & 70 \\
529.20 & 65
\end{tabular}

(curves 1 and 2 in Fig. 2b, respectively). During the polarization less than $5 \mathrm{mV}$ per min change in the potential value for pure $\mathrm{IrO}_{2}$ and $\mathrm{RuO}_{2}$ anodes was observed, that according to ${ }^{57}$ can be considered as quasi steady state on these electrodes. This resulted in only a minor change in potential (ca. $10 \mathrm{mV}$ ) at a current density of $5 \mathrm{~mA} / \mathrm{cm}^{2}$ in the polarization curves before and after polarization (Fig. 2b), which can be predominately ascribed to cleaning/re-organization during the first scan. On the other hand, the potential of the mixed $\mathrm{IrO}_{2}-\mathrm{RuO}_{2}$ anodes of the whole composition range was found to increase slowly in time. Similar behavior was also observed in the case of dimensionally stable anodes containing iridium and ruthenium oxides, for which hundreds of hours of electrolysis were required to reach steadystate conditions. ${ }^{58}$ Only 5 min of polarization leads to up to a $50 \mathrm{mV}$ increase in potential for all gradient samples (Fig. 2b), indicating a similar degree of degradation. Interestingly, the electrochemical behavior of anodes containing more than 60 at. $\%$ of Ir becomes identical to pure $\mathrm{IrO}_{2}$ after the degradation.

Electrochemical dissolution of $\mathrm{IrO}_{2}-\mathrm{RuO}_{2}$ in the potential region of oxygen evolution reaction.- - The described above electrochemical characterization has been paralleled by simultaneous recording of dissolution profiles. A typical example for an electrode containing 48 at.\% of Ir is shown in Fig. 3. One can see that in both potential sweep and steady-state polarization regimes the rate of $\mathrm{Ru}$ dissolution is significantly higher than the rate of Ir dissolution. The prevalence of ruthenium dissolution has been also observed on all other $\mathrm{IrO}_{2}-\mathrm{RuO}_{2}$ mixed oxides electrodes.

Amounts of dissolved Ir and Ru during the potential ramps and the potential step as a function of anode composition were obtained by integrating the corresponding dissolution profiles. Results are summarized in Fig. 4. Curves 1, 2 and 3 present dissolution of Ru (Fig. 4a) and Ir (Fig. 4b) in the first ramp, the final ramp, and the polarization step, respectively. In general, during the potential ramp experiments the increase in the content of Ir leads to an increase in Ir dissolution and a decrease in $\mathrm{Ru}$ dissolution. Independent of the Ir-Ru ratio in the samples, the Ru dissolution rate was higher than the Ir dissolution rate. For example, for electrodes containing 20 and 80 at.\% of Ir, the rate of $\mathrm{Ru}$ dissolution during transient conditions is 32 and 5 times higher than the Ir dissolution rate, respectively. The data on dissolution of individual $\mathrm{RuO}_{2}$ and $\mathrm{IrO}_{2}$ are in agreement with previously obtained results on the stability of pure oxides prepared by different methods, ${ }^{7,59-61}$ as well as Ru and Ir based DSA. ${ }^{58,62}$

A similar trend in the dependence of the dissolved amount of $\mathrm{Ir}$ and $\mathrm{Ru}$ on the ratio between the elements was observed during anodic polarization at $1 \mathrm{~mA} \mathrm{~cm}^{-2}$ (Fig. 4, curves 3 ). The dissolved amounts, which depend on the duration of electrolysis, are typically slightly higher than during the ramps. It is important to note that under such conditions materials containing less than 60 at. $\%$ of Ir show negligible iridium dissolution (amounts are below the detection limit of the ICPMS). Due to the lower absolute potential at $1 \mathrm{~mA} \mathrm{~cm}^{-2}$ induced by the $\mathrm{Ru}$ content, the Ir dissolution is much lower compared to for instance pure $\mathrm{IrO}_{2}$. Above a content of $60 \%$ the potential approaches values of pure $\mathrm{IrO}_{2}$, so that also the dissolution becomes traceable. Comparison of curves 1 and 3 in Fig. 4b shows that dissolution of Ir decreases 

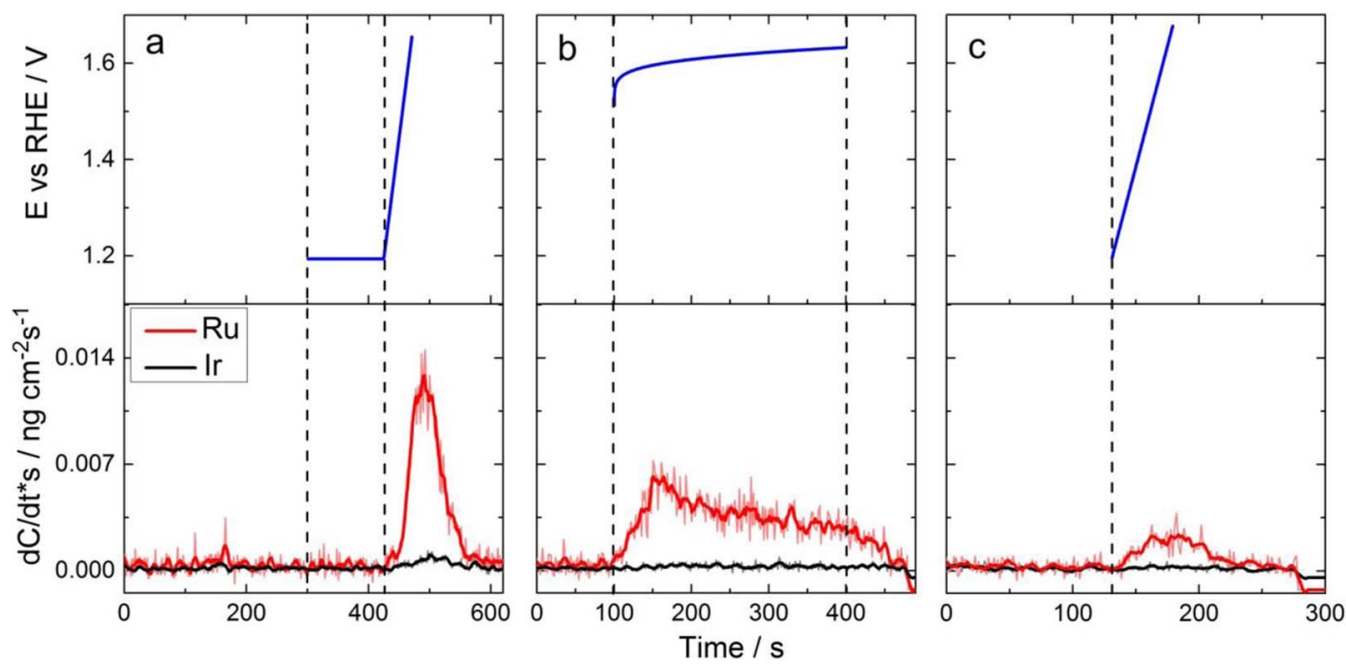

Figure 3. The applied (a, c) or measured (b) potential for the investigation of OER (upper pane) and corresponding dissolution rate curves (lower pane) plotted vs. time for an $\mathrm{IrO}_{2}-\mathrm{RuO}_{2}$ electrode containing 48 at.\% of iridium. Potential scans (a, c) were performed from $1.2 \mathrm{~V}_{\mathrm{RHE}}$ to $5 \mathrm{~mA} \mathrm{~cm}^{-2}$ with the scan rate $10 \mathrm{mV} \mathrm{s}^{-1}$ anodic polarization at $1 \mathrm{~mA} \mathrm{~cm}^{-2}$ during $5 \mathrm{~min}(\mathrm{~b})$.

after anodic polarization. Only for the pure $\mathrm{RuO}_{2}$ electrode no change in the amount of dissolved metal is observed. Note that results on transient dissolution are well in line with the data on dissolution of elements during anodic polarization at fixed current density. Hence, it may be concluded that information on dissolution of elements during potential sweep obtained using SFC connected to ICP-MS can provide a good basis for the comparison of stability of different materials,

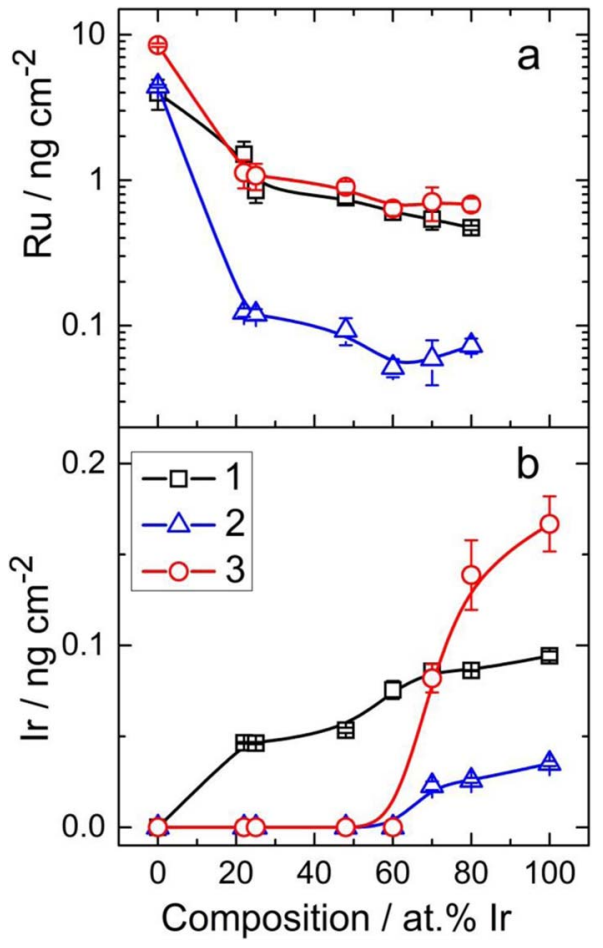

Figure 4. Amount of dissolved $\mathrm{Ru}$ (a) and Ir (b) from various $\mathrm{IrO}_{2}-\mathrm{RuO}_{2}$ electrodes measured during a single potential scan (curves 1,2) from $1.2 \mathrm{~V}_{\mathrm{RHE}}$ to a potential corresponding to $5 \mathrm{~mA} \mathrm{~cm} \mathrm{~cm}^{-2}$ before (curve 1), after (curve 2) or during $5 \mathrm{~min}$ of anodic polarization at $1 \mathrm{~mA} \mathrm{~cm}^{-2}$ (curve 3). Electrolyte: $0.1 \mathrm{M} \mathrm{H}_{2} \mathrm{SO}_{4}$. Note that the scales for the amount of dissolved element are different in (a) and (b). and may be used to predict the behavior of anodes in steady-state conditions.

\section{Discussion}

In general, results of this work are in agreement with the previously published statements on the overall improvement in catalyst stability but deterioration in OER activity with increase in iridium content in binary Ir-Ru mixed oxides. ${ }^{43-46,48,62-64}$ In the majority of those studies, both activity and stability were estimated by studying currentpotential profiles. For instance, based on an accelerated corrosion test by detecting electrode end-of-life, Kötz and Stucki showed that in comparison to pure $\mathrm{RuO}_{2}$ the corrosion rate of the mixed Ir-Ru oxide anodes is at least an order of magnitude lower. ${ }^{44}$ The authors suggested the existence of a common electronic band in the mixed oxides, leading to Ru component stabilization on the surface. Recently, this conclusion was criticized by Danilovic et al. ${ }^{47}$ These authors suggested - in particular based on dissolution data - that the observed stabilization effect is caused by surface segregation of Ir. Below we address this contradiction through a thorough analysis of XPS results and unique data on partial dissolution rates of $\mathrm{Ru}$ and $\mathrm{Ir}$.

By making a comparison of the XPS spectra taken before and after the anodic polarization, we have not observed any change in Ir to $\mathrm{Ru}$ ratio. On the other hand, the $\mathrm{O} 1 \mathrm{~s}$ line clearly shifts to higher binding energies, approaching a value corresponding to pure $\mathrm{IrO}_{2}$. Indeed, this may be an indirect indication of an increase in the amount of iridium oxide on the electrode surface. Besides the peak position, the ratio between the $\mathrm{O}$ and $\mathrm{OH}$ groups in the $\mathrm{O}$ 1s spectra was sensitive to electrode composition, but only for the gradients with Ir content lower than 60 at.\%. Similar behavior was recently observed in an Ir-Ni mixed oxide system. ${ }^{65}$ Interestingly, unlike for the Ir-Ni system in which leaching of nickel leads to an increase in activity, the electrocatalytic activity of $\mathrm{Ir}-\mathrm{Ru}$ oxides was found to deteriorate. As can be seen in Fig. 2b, potentials of all Ir-Ru mixed oxide anodes tend to increase in time during OER. For example, the activity of the electrode containing 25 at.\% of $\mathrm{Ir}$, which was close to pure $\mathrm{RuO}_{2}$ in the beginning, decreased dramatically after anodic polarization approaching the value corresponding to that of an untreated anode with 60 at.\% of Ir. This can be attributed to Ru dissolution, which unlike $\mathrm{Ni}$, is an active material in OER. Indeed, from Fig. 3 and Fig. 4 it is clear that in comparison to Ir, the rate of Ru dissolution is significantly higher for all mixed oxides. Moreover, while in some electrodes Ir is stabilized, Ru constantly dissolves, although the rate decreases with time (Fig. 4). Hence, it can be speculated that the surface concentration 
of Ru should approach zero over time. In this, Ir-Ru behaves similar to fuel cell alloy catalysts such as Co-Pt in which the Pt-rich shell protects the alloy core from constant leaching of less noble cobalt. Using dissolution data, one can estimate if variation in activity, e.g. for the electrode containing initially 25 at. $\%$ of $\mathrm{Ir}$, is proportional to the change in Ir surface concentration. Assuming that in the initial electrode surface and bulk the concentration is equal, such change in activity could be attributed to a gain in Ir concentration from 25 to 60 at.\%. A back-of-the-envelope calculation taking into account the surface densities of Ir and Ru atoms in the oxide lattice shows, however, that it is only less than 2 at. $\%$ of $\mathrm{Ru}$ in a monolayer that was dissolved. The same non-linearity in activity and dissolution change was obtained for all Ir-Ru mixed oxide electrodes.

One can suggest several explanations for this phenomenon. First of all, our assumption that the surface and bulk compositions are equal can be incorrect. Indeed, segregation of Ir onto the topmost atomic layers during thermal treatment was suggested previously. ${ }^{47}$ If this is the case, then dissolution of even a small amount of Ru may lead to a significant depletion in the $\mathrm{Ru}$ surface concentration and, hence, an increase in both overpotential of OER and Tafel slope. It should be noted, however, that in the current work the temperature of thermal treatment is far lower than in the studies of Danilovic et al. ${ }^{47}$ Therefore, taking also into account the similarity in Ir and Ru atomic radii and the higher diffusion rate of oxygen in the Ru lattice, segregation of Ir should not be crucial. Another possible explanation of the observed deterioration of electrocatalytic properties can be a rearrangement of $\mathrm{Ir}$ and $\mathrm{Ru}$ atoms in the topmost atomic layers caused by anodic polarization, resulting in diffusion of thermodynamically more stable Ir to the surface. Independent of the exact cause, annealing or polarization, it seems likely that the decrease in electrode activity is related to Ir surface segregation. That is, activity and stability are determined by the amount of $\mathrm{Ir}$ and $\mathrm{Ru}$ on the surface and their individual properties. Taking into account the higher affinity of $\mathrm{Ru}$ to oxygen-containing particles in comparison to $\mathrm{Ir}$, this may indicate that the original properties of Ir and Ru active sites in mixed oxides remain the same. In other words, adsorption energies of oxygenated species on $\mathrm{Ru}$ and $\mathrm{Ir}$ sites are different. In this case, an increase in Ir content on the surface results in adsorption of oxygen-containing radicals mainly on Ir active sites and an increase in overpotential and Tafel slope of OER. Taking into account the parallelism between OER and dissolution, ${ }^{59,66}$ the amount of dissolved Ir should increase with Ir content (Fig. 4b). At the same time, increase of Ir concentration leads to decrease in the number of $\mathrm{Ru}$ active sites available for adsorption, lowering the probability of $\mathrm{Ru}(\mathrm{VIII})$ intermediates formation and, therefore, hindering of Ru dissolution, as observed in Fig. 4a. It should be noted here, that thermally prepared oxides used in the current work are similar to those employed by Danilovic et al. On the other hand, Kötz and Stucki used oxide obtained by reactive sputtering. The absence of a common electronic band might originate as a product of the differences in synthesis methods.

Although long-term durability is still to be proven, taking into account the relatively low price of $\mathrm{Ru}$, addition of this element to iridium oxide may be justified, at least to decrease the Ir loading. It is clear however, that the gain in activity, if any, is ephemeral, and continuous leaching of Ru can be considered as a severe problem. In case Ir and energy costs are the main issues, the use of $\mathrm{Ru}$ can be probably tolerated. In other cases, however, mixed $\mathrm{IrO}_{2}$ oxides based on much more stable oxides such as $\mathrm{TiO}_{2}$ or $\mathrm{SnO}_{2}$ may be considered as a promising option..$^{21,27,67,68} \mathrm{~A}$ comprehensive study on the activity and stability relationship for such mixed oxide anodes in acidic media will be a topic of a future work.

\section{Conclusions}

Stability and activity toward OER of Ir-Ru mixed oxides over the complete composition range were examined using the SFC-ICP-MS set-up. Obtained results on dissolution of Ir and Ru strongly suggest that both elements on the electrode surface keep their original properties in the mixed oxide system. Hence, an increase in the amount of the more active ruthenium oxide in the active layer of electrodes leads to an increase in the overall activities of the anodes. However, surface $\mathrm{Ru}$ is not stabilized, which leads to a significant rate of Ru dissolution regardless of the electrode composition. Surface segregation of Ir in an additional process, e.g. bulk to surface diffusion of Ir, cannot be ruled out as even dissolution of an equivalent to a few percent of a monolayer of Ru results in significantly reduced electrocatalytic activity. In this connection, application of Ir-Ru mixed oxides as anodes for oxygen evolution reaction is questionable and depends on the real application requirements.

\section{Acknowledgments}

The authors thank A. Mingers for experimental assistance. O.K. acknowledges financial support from the Alexander von Humboldt Foundation. The authors acknowledge the MAXNET Energy research initiative of the Max Planck Society for financial support.

\section{References}

1. S. A. Sherif, F. Barbir, and T. N. Veziroglu, Solar Energy, 78, 647 (2005).

2. A. R. Zeradjanin, A. A. Topalov, Q. Van Overmeere, S. Cherevko, X. Chen, E. Ventosa, W. Schuhmann, and K. J. J. Mayrhofer, RSC Advances, 4, 9579 (2014).

3. A. Djafour, M. Matoug, H. Bouras, B. Bouchekima, M. S. Aida, and B. Azoui, International Journal of Hydrogen Energy, 36, 4117 (2011).

4. L. M. Gandía, R. Oroz, A. Ursúa, P. Sanchis, and P. M. Diéguez, Energy \& Fuels, 21, 1699 (2007).

5. F. Barbir, Solar Energy, 78, 661 (2005).

6. M. Carmo, D. L. Fritz, J. Mergel, and D. Stolten, International Journal of Hydrogen Energy, 38, 4901 (2013).

7. S. Cherevko, S. Geiger, O. Kasian, N. Kulyk, J.-P. Grote, A. Savan, B. R. Shrestha, S. Merzlikin, B. Breitbach, A. Ludwig, and K. J. J. Mayrhofer, Catalysis Today, 262, 170 (2016).

8. S. Cherevko, A. R. Zeradjanin, A. A. Topalov, N. Kulyk, I. Katsounaros, and K. J. J. Mayrhofer, ChemCatChem, 6, 2219 (2014).

9. N. Danilovic, R. Subbaraman, K.-C. Chang, S. H. Chang, Y. J. Kang, J. Snyder, A. P. Paulikas, D. Strmcnik, Y.-T. Kim, D. Myers, V. R. Stamenkovic, and N. M. Markovic, The journal of physical chemistry letters, 5, 2474 (2014).

10. F. Moradi and C. Dehghanian, Progress in Natural Science: Materials International, 24, 134 (2014).

11. J. Llopis, I. M. Tordesillas, and J. M. Alfayate, Electrochimica acta, 11, 623 (1966)

12. C. Iwakura, K. Hirao, and H. Tamura, Electrochimica Acta, 22, 329 (1977).

13. R. Kötz, H. Neff, and S. Stucki, Journal of The Electrochemical Society, 131, 72 (1984).

14. D. Marljan, D. Cukman, M. Vukovic, and M. Milun, Journal of Materials Science, 30, 3045 (1995)

15. C. C. McCrory, S. Jung, J. C. Peters, and T. F. Jaramillo, Journal of the American Chemical Society, 135, 16977 (2013).

16. C. C. McCrory, S. Jung, I. M. Ferrer, S. M. Chatman, J. C. Peters, and T. F. Jaramillo, Journal of the American Chemical Society, 137, 4347 (2015).

17. S. Zhao, H. Yu, R. Maric, N. Danilovic, C. B. Capuano, K. E. Ayers, and W. E. Mustain, Journal of The Electrochemical Society, 162, F1292 (2015)

18. T. P. Luxton, M. J. Eick, and K. G. Scheckel, Journal of colloid and interface science, 359, 30 (2011).

19. J. Juodkazyte, R. Vilkauskaitè, B. Šebeka, and K. Juodkazis, Transactions of the IMF, 85, 194 (2007).

20. T. Reier, M. Oezaslan, and P. Strasser, ACS Catalysis, 2, 1765 (2012).

21. J. Xu, G. Liu, J. Li, and X. Wang, Electrochimica Acta, 59, 105 (2012)

22. N. Mamaca, E. Mayousse, S. Arrii-Clacens, T. W. Napporn, K. Servat, N. Guillet, and K. B. Kokoh, Applied Catalysis B: Environmental, 111-112, 376 (2012).

23. S. Fierro, A. Kapałka, and C. Comninellis, Electrochemistry Communications, 12 172 (2010).

24. R. F. Savinell, R. L. Zeller, and J. A. Adams, Journal of The Electrochemical Society, 137, 489 (1990)

25. J. Rossmeisl, A. Logadottir, and J. K. Nørskov, Chemical Physics, 319, 178 (2005).

26. J. Rossmeisl, Z. W. Qu, H. Zhu, G. J. Kroes, and J. K. Nørskov, Journal of Electroanalytical Chemistry, 607, 83 (2007).

27. S. Fierro, T. Nagel, H. Baltruschat, and C. Comninellis, Electrochemistry Communications, 9, 1969 (2007).

28. J. Juodkazyte, B. Šebeka, I. Valsiunas, and K. Juodkazis, Electroanalysis, 17, 947 (2005).

29. E. Antolini, ACS Catalysis, 4, 1426 (2014)

30. H. Over, A. P. Seitsonen, E. Lundgren, M. Smedh, and J. N. Andersen, Surface Science, 504, L196 (2002).

31. K. A. Stoerzinger, L. Qiao, M. D. Biegalski, and Y. Shao-Horn, The journal of physical chemistry letters, 5, 1636 (2014).

32. K. Macounova, M. Makarova, and P. Krtil, Electrochemistry Communications, 11 1865 (2009)

33. J. Hu, International Journal of Hydrogen Energy, 29, 791 (2004). 
34. R. Viganoò, J. Taraszewska, A. Daghetti, and S. Trasatti, Journal of Electroanalytical Chemistry and Interfacial Electrochemistry, 182, 203 (1985).

35. P. Steegstra, M. Busch, I. Panas, and E. Ahlberg, The Journal of Physical Chemistry $C, \mathbf{1 1 7}, 20975$ (2013).

36. V. V. Gorodetskii and V. A. Neburchilov, Russian Journal of Electrochemistry, 39 1111 (2003).

37. A. Benedetti, S. Polizzi, P. Riello, A. De Battisti, and A. Maldotti, Journal of Materials Chemistry, 1, 511 (1991).

38. F. I. Mattos-Costa, P. de Lima-Neto, S. A. S. Machado, and L. A. Avaca, Electrochimica Acta, 44, 1515 (1998)

39. A. T. Marshall and R. G. Haverkamp, Electrochimica Acta, 55, 1978 (2010).

40. R. R. Daniels, G. Margaritondo, C. A. Georg, and F. Lévy, Physical Review B, 29, 1813 (1984).

41. W. Du, N. A. Deskins, D. Su, and X. Teng, ACS Catalysis, 2, 1226 (2012).

42. L.-E. Owe, M. Tsypkin, K. S. Wallwork, R. G. Haverkamp, and S. Sunde, Electrochimica Acta, 70, 158 (2012).

43. J. M. Roller, M. Josefina Arellano-Jiménez, R. Jain, H. Yu, C. Barry Carter, and R. Maric, Journal of The Electrochemical Society, 160, F716 (2013).

44. R. Kötz and S. Stucki, Electrochimica Acta, 31, 1311 (1986).

45. J. Cheng, H. Zhang, G. Chen, and Y. Zhang, Electrochimica Acta, 54, 6250 (2009).

46. C. Angelinetta, S. Trasatti, L. D. Atanasoska, and R. T. Atanasoski, Journal of Electroanalytical Chemistry and Interfacial Electrochemistry, 214, 535 (1986).

47. N. Danilovic, R. Subbaraman, K. C. Chang, S. H. Chang, Y. Kang, J. Snyder, A. P. Paulikas, D. Strmcnik, Y. T. Kim, D. Myers, V. R. Stamenkovic, and N. M. Markovic, Angewandte Chemie International Edition, 53, 14016 (2014).

48. G. Li, H. Yu, W. Song, X. Wang, Y. Li, Z. Shao, and B. Yi, International Journal of Hydrogen Energy, 37, 16786 (2012).

49. S. Siracusano, N. Van Dijk, E. Payne-Johnson, V. Baglio, and A. S. Aricò, Applied Catalysis B: Environmental, 164, 488 (2015).

50. S. O. Klemm, A. Karschin, A. K. Schuppert, A. A. Topalov, A. M. Mingers, I. Katsounaros, and K. J. J. Mayrhofer, Journal of Electroanalytical Chemistry, 677680, 50 (2012).

51. A. A. Topalov, I. Katsounaros, J. C. Meier, S. O. Klemm, and K. J. Mayrhofer, The Review of scientific instruments, 82, 114103 (2011).

52. H. J. Lewerenz, S. Stucki, and R. Kötz, Surface Science, 126, 463 (1983).
53. J. Augustynski, M. Koudelka, J. Sanchez, and B. E. Conway, Journal of Electroanalytical Chemistry and Interfacial Electrochemistry, 160, 233 (1984).

54. V. Pfeifer, T. E. Jones, J. J. Velasco Vélez, C. Massué, R. Arrigo, D. Teschner, F. Girgsdies, M. Scherzer, M. T. Greiner, J. Allan, M. Hashagen, G. Weinberg, S. Piccinin, M. Hävecker, A. Knop-Gericke, and R. Schlögl, Surface and Interface Analysis, 48, 261 (2016).

55. V. Pfeifer, T. E. Jones, J. J. Velasco Velez, C. Massue, M. T. Greiner, R. Arrigo, D. Teschner, F. Girgsdies, M. Scherzer, J. Allan, M. Hashagen, G. Weinberg, S. Piccinin, M. Havecker, A. Knop-Gericke, and R. Schlogl, Physical Chemistry Chemical Physics, 18, 2292 (2016).

56. D. Rochefort, P. Dabo, D. Guay, and P. M. A. Sherwood, Electrochimica Acta, 48, 4245 (2003)

57. A. Damjanovic, A. Dey, and J. O. M. Bockris, Journal of The Electrochemical Society, 113, 739 (1966)

58. V. V. Gorodetskii and V. A. Neburchilov, Russian Journal of Electrochemistry, 41, 971 (2005).

59. Y. M. Kolotyrkin, V. V. Losev, and A. N. Chemodanov, Materials Chemistry and Physics, 19, 1 (1988)

60. H. Tamura and C. Iwakura, International Journal of Hydrogen Energy, 7, 857 (1982).

61. C. Iwakura, K. Hirao, and H. Tamura, Electrochimica Acta, 22, 335 (1977).

62. V. V. Gorodetskii and V. A. Neburchilov, Russian Journal of Electrochemistry, 43, 223 (2007).

63. E. Mayousse, F. Maillard, F. Fouda-Onana, O. Sicardy, and N. Guillet, International Journal of Hydrogen Energy, 36, 10474 (2011)

64. T. M. C. Felix, S. Pasupathi, B. Bladergroen, and V. Linkov, Int. J. Electrochem. Sci., 7, 12064 (2012)

65. T. Reier, Z. Pawolek, S. Cherevko, M. Bruns, T. Jones, D. Teschner, S. Selve, A. Bergmann, H. N. Nong, R. Schlögl, K. J. J. Mayrhofer, and P. Strasser, Journal of the American Chemical Society, 137, 13031 (2015).

66. T. Binninger, R. Mohamed, K. Waltar, E. Fabbri, P. Levecque, R. Kotz, and T. J. Schmidt, Scientific reports, $\mathbf{5}, 12167$ (2015).

67. S. Trasatti, Electrochimica Acta, 29, 1503 (1984).

68. V. V. Gorodetskii, V. A. Neburchilov, and V. I. Alyab'eva, Russian Journal of Electrochemistry, 41, 1111 (2005) 